\title{
Expression of retinoid $X$ receptor $\alpha$ is decreased in 3'-methyl-4-dimethylaminoazobenzene-induced hepatocellular carcinoma in rats
}

\author{
NOBUHIRO ANDO $^{1}$, MASAHITO SHIMIZU ${ }^{1}$, MASATAKA OKUNO $^{1}$, RIE MATSUSHIMA-NISHIWAKI $^{1}$, \\ HISASHI TSURUMI ${ }^{1}$, TAKUJI TANAKA ${ }^{2}$ and HISATAKA MORIWAKI ${ }^{1}$ \\ ${ }^{1}$ Department of Medicine, Gifu University School of Medicine, Gifu 501-1194; \\ ${ }^{2}$ Department of Oncologic Pathology, Kanazawa Medical University, Ishikawa 920-0293, Japan
}

Received May 28, 2007; Accepted July 17, 2007

\begin{abstract}
The identification of the specific molecular targets, which underlie liver carcinogenesis is essential for the establishment of an effective strategy for the prevention and/or treatment of hepatocellular carcinomas (HCCs). We previously found that a malfunction of $\mathrm{RXR} \alpha$ due to its aberrant phosphorylation was associated with the development of HCCs. However, it has remained unclear whether the abnormalities in the expression of $\mathrm{RXR} \alpha$ or the other retinoid receptors play a role in the early stage of liver carcinogenesis. The present study was designed to determine whether alterations in the expression of RXR $\alpha$ and the other retinoid receptors $\operatorname{RAR} \alpha$ and RAR $\beta$ are involved in hepatocarcinogenesis using a 3'methyl-4-dimethylaminoazobenzene (3'-MeDAB)-induced rat liver carcinogenesis model. We found that immunohistochemical expression of $\mathrm{RXR} \alpha$ was decreased in liver cell tumors (HCCs and adenoma) and glutathione S-transferase placental form (GST-P)-positive foci, which is a precancerous lesion of HCC, when compared with the non-cancerous tissues. Western blot and RT-PCR analyses revealed a progressive decrease in the expression levels of $\operatorname{RXR} \alpha$, RAR $\alpha$, and RARß proteins and their mRNAs in $3^{\prime}-$ MeDAB-induced HCCs and their surrounding tissues, when
\end{abstract}

Correspondence to: Dr Masahito Shimizu, Department of Medicine, Gifu University School of Medicine, 1-1 Yanagido, Gifu 501-1194, Japan

E-mail: shimim-gif@umin.ac.jp

Abbreviations: $\mathrm{RXR}$, retinoid $\mathrm{X}$ receptor; RAR, retinoic acid receptor; HCC, hepatocellular carcinoma; 3'-MeDAB, 3'-methyl-4dimethylaminoazobenzene; HBV, hepatitis B virus; HCV, hepatitis $\mathrm{C}$ virus; RXRE, retinoid $\mathrm{X}$ receptor responsive element; $\mathrm{H} \& \mathrm{E}$, hematoxylin and eosin; GST-P, glutathione S-transferase placental form; PCNA, proliferating cell nuclear antigen; GAPDH, glyceraldehydes-3-phosphate dehydrogenase

Key words: $\mathrm{RXR} \alpha, 3$ '-MeDAB, liver tumor, $\beta$-catenin, cyclin D1 compared with the normal liver tissues from the control group. Moreover, the expression level of $\beta$-catenin, the heterodimeric partner for both $\operatorname{RXR} \alpha$ and $\operatorname{RAR} \alpha$, was immunohistochemically observed in the cytoplasm and, in some cases, in the nucleus of HCC cells. The nuclear expression of cyclin D1, the downstream target molecule of $B$-catenin, was also increased in HCC cells when compared with their adjacent normal appearing tissues. Our findings suggest that loss of retinoid receptors, especially $\mathrm{RXR} \alpha$, plays a critical role in the chemically-induced rat liver carcinogenesis and this might be associated with the activation of $\beta$-catenin-related signaling pathway.

\section{Introduction}

Hepatocellular carcinoma (HCC) is one of the most frequently occurring cancers worldwide. The development of HCC is generally associated with chronic inflammation of the liver induced by a persistent infection with hepatitis viruses $\mathrm{B}$ (HBV) and $\mathrm{C}(\mathrm{HCV})$. Although the precancerous stage of HCC is well-defined, the prognosis for this cancer is poor because the rates of occurrence and recurrence for HCC in patients with underlying cirrhosis are very high $(1,2)$ and there are no established agents for the effective treatment of this cancer. Therefore, there is a critical need to develop effective strategies for the chemoprevention and chemotherapy of HCC. In addition, the clarification of the underlying mechanisms of liver carcinogenesis, i.e., the identification of the specific molecular target which plays a role in the development of $\mathrm{HCC}$, is important to establish both chemopreventive and chemotherapeutic agents for this malignancy.

Retinoids, a group of structural and functional analogues of vitamin A, exert fundamental effects on the regulation of epithelial cell growth, differentiation, and development primarily through two distinct nuclear receptors, retinoic acid receptors (RARs) and retinoid X receptors (RXRs), both of which are composed of three subtypes $(\alpha, \beta$, and $\gamma)(3,4)$. Abnormalities in the expression and function of both RARs and RXRs play an important role in influencing the growth of various epithelial malignancies, including HCC. RXR $\alpha$ is able to bind to the enhancer element of HBV (5). The RAR $\alpha$ 
gene is located near one of the integration sites of HBV and its expression is induced in HCC (6). The RARß gene can also be an integration site of HBV (7). We previously found that a malfunction of $\operatorname{RXR} \alpha$ due to aberrant phosphorylation is associated with development of HCC. Therefore, RXR $\alpha$ is phosphorylated in human HCC tissues as well as in human HCC cell lines, and the phosphorylated form of RXR $\alpha$ $(\mathrm{p}-\mathrm{RXR} \alpha)$ lost its transcriptional activity via the retinoid $\mathrm{X}$ receptor responsive element (RXRE) $(8,9)$. The $\mathrm{p}-\mathrm{RXR} \alpha$ protein is resistant to ubiquitination and proteasome-mediated degradation in human HCC tissue (10). These findings suggest that the accumulation of such a non-functional p-RXR $\alpha$ protein interferes with the function of the remaining normal $\mathrm{RXR} \alpha$ in a dominant-negative manner, thereby promoting the growth of hepatoma cells (8). However, it has remained unclear whether abnormalities in the expression levels of the retinoid receptors may play a role in the early stage of liver carcinogenesis.

In the current study, we examined whether the expression of $\operatorname{RXR} \alpha, \operatorname{RAR} \alpha$, and RAR $\beta$ are altered during hepatocarcinogenesis using a rat model initiated with 3'-methyl-4dimethylaminoazobenzene (3'-MeDAB) that is one of the useful animal models for investigating liver tumorigenesis $(11,12)$, specifically focusing on $\mathrm{RXR} \alpha$ expression in glutathione $S$-transferase placental form (GST-P)-positive foci that is a precancerous lesion for HCC because we presumed that this receptor plays a critical role in the development of $\operatorname{HCC}(8,9)$.

\section{Materials and methods}

Animals and treatment. A total of 46 male Fischer-strain (F344/N Slc) rats aged 6 weeks (Japan SLC, Inc., Shizuoka, Japan) were divided into two experimental groups (the $3^{\prime}$-MeDAB and control groups). In order to induce liver neoplasms, one group (38 rats) was fed the pellet diet (MF, Oriental Yeast Co., Tokyo, Japan) containing 0.06\% 3'-MeDAB (Tokyo Kasei Kogyo Co., Tokyo, Japan) for 16 weeks as described previously $(11,13)$. The other group (8 rats) was fed the MF diet without 3'-MeDAB. In order to identify the initial histological changes induced by 3'$\mathrm{MeDAB}$ in the liver, 4 rats from each group were sacrificed at 4 weeks after the commencement of the experiment, whereas the remaining 34 rats in the $3^{\prime}-\mathrm{MeDAB}$ group and 8 rats in the control group were sacrificed at the end of the study (week 16). All of the rats were sacrificed by a deep anesthesia with sodium pentobarbital and exsanguination. The livers were then removed, and three slices $(2 \mathrm{~mm})$ were taken from each sublobe and fixed in $10 \%$ buffered formalin for histopathological examination.

Histopathological and immunohistochemical analysis. The serial sections $(3 \mu \mathrm{m})$ from each slice embedded in paraffin were prepared for the histopathological and immunohistochemical analysis. One section was stained with hematoxylin and eosin (H\&E) for diagnosing liver lesions, and the others were used for immunohistochemistry for GST-P, proliferating cell nuclear antigen (PCNA), RXR $\alpha$, RAR $\alpha$, RARß, $\beta$-catenin, and cyclin D1. A pathologist (T.T.) who was not aware which tissues belonged in each group, diagnosed the lesions histology and immunohistochemical stainability of antibodies. The deparaffinized sections were incubated with primary antibodies including a rabbit polyclonal anti-GST-P antibody (1:1,000 dilution, MBL, Nagoya, Japan), a mouse monoclonal anti-PCNA antibody (1:50 dilution, Dako, Kyoto, Japan), a rabbit polyclonal anti-RXR $\alpha$ antibody (1:200 dilution, Santa Cruz Biotechnology, Santa Cruz, CA, USA), a rabbit polyclonal anti-RAR $\alpha$ antibody (1:200 dilution, Santa Cruz Biotech-nology), a rabbit polyclonal anti-RAR $\alpha$ antibody (1:200 dilution, Santa Cruz Biotechnology), a mouse monoclonal anti- $\beta$-catenin antibody (1:1000 dilution, Transduction Lab-oratories, Lexington, KY, USA), and a mouse monoclonal anti-cyclin D1 antibody (1:200 dilution, Dako, Japan) respectively, overnight in a humidified chamber at $4^{\circ} \mathrm{C}$. The sections were then washed with Tris- $\mathrm{HCl}$, and incubated with respective secondary antibodies, processed for immunohisto-chemical analysis using the LSAB universal kit (Dako, Glostrup, Denmark) as described previously (11), according to the manufacturer's instructions. On the control sections, incubation with the primary antibodies was omitted.

Protein extraction and Western blot analysis. The preparation of protein lysates and Western blot analysis for $\operatorname{RXR} \alpha, \operatorname{RAR} \alpha$, and RARß were performed as described previously (8). Equal amounts of protein lysates $(20 \mu \mathrm{g})$ from the liver of the rats of two experimental groups, which were sacrificed at 16 weeks after the start of the experiment, were used for a Western blot analysis. The protein concentrations in the sample were determined using the BCA protein assay reagent kit (Pierce, Rockford, IL). A rabbit monoclonal antibody against glyceraldehyde-3-phosphate dehydrogenase (GAPDH) was from Chemicon International (Temecula, CA). An antibody to GAPDH was used as a loading control. Each membrane was developed using an ECL-enhanced chemiluminescence system (Amersham Biosciences, Piscataway, NJ).

RNA extraction and semiquantitative RT-PCR analysis. The RNA extraction and RT-PCR analysis were performed as described previously (11). The total RNA was extracted from the liver of rats belonging the 3'-MeDAB and control groups that were sacrificed at 16 weeks after the start of the experiment, using Isogen (Wako Pure Chemical, Osaka, Japan). The cDNA was amplified from $1 \mu \mathrm{g}$ of the total RNA using a high fidelity RNA PCR kit (Takara Biomedicals, Shiga, Japan), according to the manufacturer's instructions. RXR $\alpha-$, RAR $\alpha-$, RARß-, and GAPDH-specific primer sets were as previously described (14-16). Each amplification cycle consisted of $30 \mathrm{sec}$ at $94^{\circ} \mathrm{C}$ for denaturation, $30 \mathrm{sec}$ at $56^{\circ} \mathrm{C}$ for primer annealing, and $1 \mathrm{~min}$ at $72^{\circ} \mathrm{C}$ for extension. By using a PCR Thermal Cycler 480 (Takara Biomedicals), the 35-, 40-, and 30-cycle rounds of PCR were chosen for analysis of expression of RXR $\alpha, R A R \alpha$, and RAR $\beta$ mRNAs, respectively. After PCR amplification, the fragments were run on $2 \%$ agarose gels and stained with ethidium bromide. The intensities of the mRNA bands were then quantified using the NIH Image software package version 1.61.

Statistical analysis. The data are expressed as the means \pm SD. The statistical significance of the difference in the mean values 


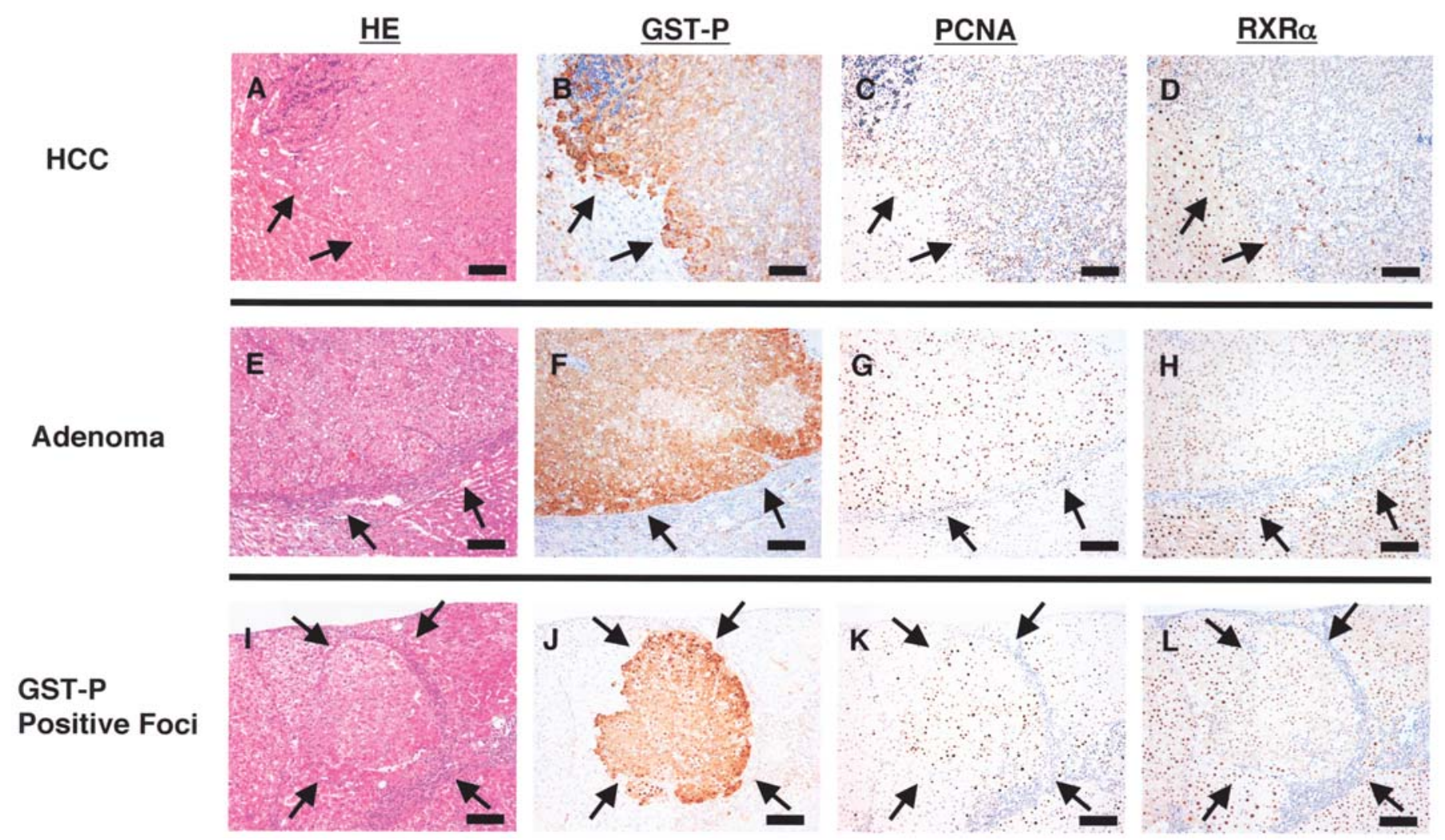

Figure 1. Immunohistochemistry of GST-P, PCNA, and RXR $\alpha$ in 3'-MeDAB-induced rat liver tumors. F344/N rats were fed with 3'-MeDAB-containing diet for 4 or 16 weeks. The livers were removed, and fixed in $10 \%$ buffered formalin at weeks 4 and 16 . The serial sections were then prepared and stained with H\&E (A, E, and I) or were used for immunohistochemical analyses for GST-P (B, F, and J), PCNA (C, G, and K), and RXR $\alpha$ (D, H, and L). The samples for HCC and adenoma were obtained from the liver of rats that received the 3'-MeDAB diet for 16 weeks. The samples for GST-P positive foci were obtained from the liver of rats fed the 3'-MeDAB diet for 4 weeks. Bars indicate scale of $10 \mu \mathrm{m}$.

was assessed using one-way ANOVA, followed by Sheffe's t-test.

\section{Results}

The immunohistochemical expression of RXRa in 3'-MeDABinduced liver lesions. Since we previously found that the abnormalities in the expression and the function of $\operatorname{RXR} \alpha$ play a critical role in the development of human $\operatorname{HCC}(8,9)$, the immunohistochemical expression of $\operatorname{RXR} \alpha$ was initially examined in the liver of rats treated with 3 '-MeDAB. In HCCs that developed in rats sacrificed at week 16 (Fig. 1A) showed altered expression of RXR $\alpha$. Thus, the 7 HCCs examined showed a significant decrease in the expression of RXR $\alpha$ in HCC tissue, when compared to the non-cancerous tissue (Fig. 1D). We also observed that the immunohistochemical expression of GST-P (Fig. 1B) and PCNA (Fig. 1C), the cell proliferation biomarker, was greatly increased in HCCs, when compared to their surrounding non-cancerous liver tissue.

The liver cell adenomas that were found at week 16 (Fig. $1 \mathrm{E})$, showed a remarkable increase in the expression of GST-P (Fig. 1F) and PCNA (Fig. 1G). However, there was a decrease in the immunohistochemical stainability of $\mathrm{RXR} \alpha$ (Fig. 1H) in 7 adenomas examined as found in HCCs, when compared to their surrounding non-tumorous regions. All of GST-P positive foci (Figs. 1I and 1J) that were developed in rats sacrificed at week 4 possessed overexpression of PCNA
(Fig. 1K), when compared with their surrounding normalappearing liver cells. Among them, 5 GST-P positive foci (25\%) expressed low immunohistochemical expression of RXR $\alpha$ protein (Fig. 1L).

The expression levels of $R X R \alpha, R A R \alpha$, and $R A R \beta$ proteins and $m R N A s$ in 3'-MeDAB-induced HCCs. Since GST-P positive foci were too small to determine the expression levels of RXR $\alpha$ and the other retinoid receptors, such as RAR $\alpha$ and RARß, we analyzed their expression in HCCs and their surrounding normal-appearing liver tissues. As shown in Fig. 2, Western blot analysis of the expression levels of the RXR $\alpha, \operatorname{RAR} \alpha$, and RARß proteins revealed a marked decrease in the expression of these receptor proteins in HCCs that developed in rats fed the 3'-MeDAB diet and sacrificed at week 16 . The normal appearing liver tissues also showed a significant decrease in the expression of these proteins (Fig. 2A-C, upper panels). When compared to the liver of control group, subsequent semiquantitative RT-PCR analysis indicated that the decreases in the expression of $\mathrm{RXR} \alpha, \mathrm{RAR} \alpha$, and $\mathrm{RAR} \beta$ proteins were paralleled with the decrease in their mRNAs (Fig. 2A-C, lower panels). These findings suggest that the downregulation of expression for these retinoid receptors occurred, at least in part, in the levels of their mRNAs.

The expression levels of $\beta$-catenin and cyclin D1 proteins in 3'-MeDAB-induced HCCs. We thereafter examined the expression pattern of $\beta$-catenin because this protein is a hetero- 
A
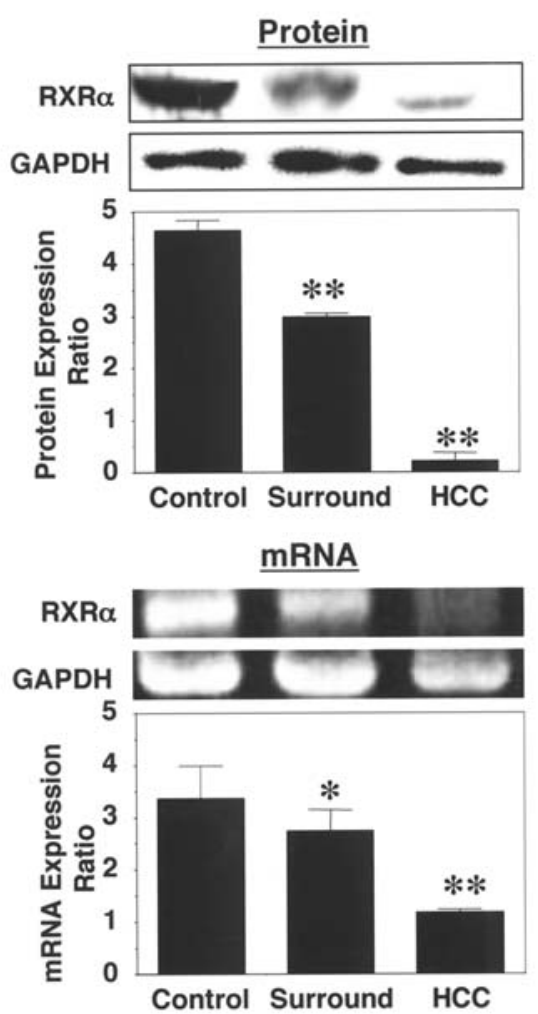

B
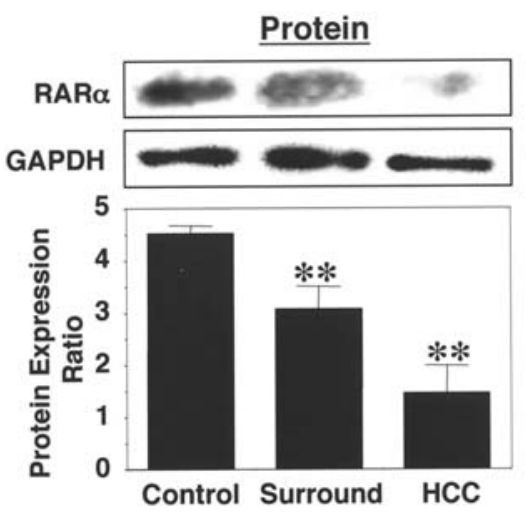

Control Surround HCC
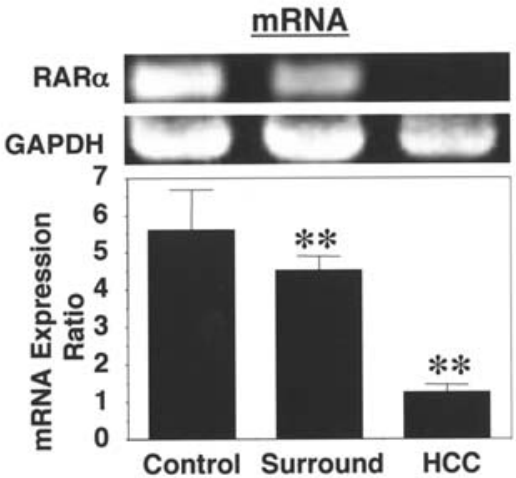

C
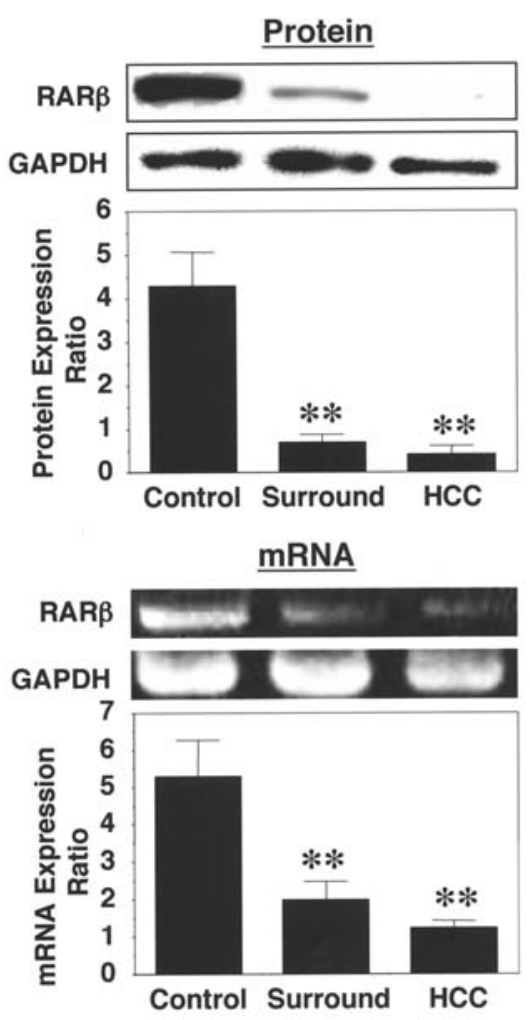

Figure 2. Expression levels of RXR $\alpha, \operatorname{RAR} \alpha$, and RARß in HCCs induced by 3'-MeDAB in rats that were sacrificed at week 16. F344/N rats were fed with the diet with or without 3 '-MeDAB for 16 weeks and their livers were removed. The proteins and mRNAs were extracted from the HCCs, their surrounding normal-appearing tissues, and liver tissues without lesions from the control group. The extracted proteins were analyzed by Western blotting with anti-RXR $\alpha-$ (A, upper panel), anti-RAR $\alpha$ - (B, upper panel), or anti-RARß- (C, upper panel) specific antibodies. An antibody to GAPDH was used as a loading control. The extracted mRNAs were examined by RT-PCR analysis with the RXR $\alpha$ - (A, lower panel), RAR $\alpha$ - (B, lower panel), or RARß- (C, lower panel) specific primers, and GAPDH specific primers were used as a control. The results obtained from Western blotting and RT-PCR analyses were quantitated by densitometry and are displayed as bar graph (mean $\pm \mathrm{SD}$ ). ${ }^{*} \mathrm{p}<0.05,{ }^{* *} \mathrm{p}<0.01$ as compared to normal tissue. Repeat Western blots and RT-PCR assays gave similar results.

$\underline{\text { HE }}$

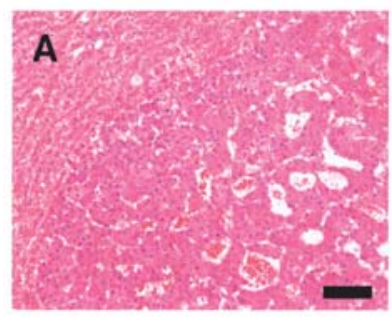

B-catenin (low magnification)

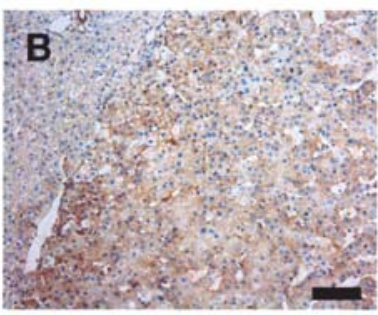

Cyclin D1 (low magnification)

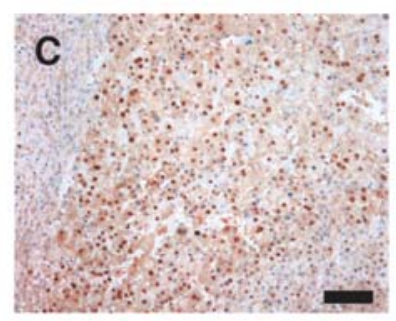

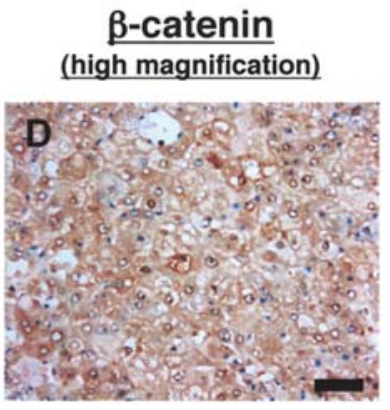

Cyclin D1 (high magnification)

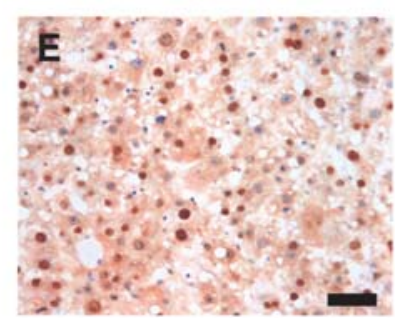

Figure 3. Immunohistochemical expression levels of B-catenin and cyclin D1 in HCCs developed in rats fed with the 3'-MeDAB diet for 16 weeks. The serial sections were prepared from the HCCs of rats that were sacrificed at week 16, and they were processed for H\&E staining (A) and immunohistochemistry for B-catenin (B and D) and cyclin D1 (C and E). (B) and (C) are low magnification and (D) and (E) are high magnification. Bars indicate scale of $10 \mu \mathrm{m}(\mathrm{A}, \mathrm{B}$, and C) and $20 \mu \mathrm{m}$ (D and E). 
dimeric partner for both $\operatorname{RXR} \alpha(17,18)$ and $\operatorname{RAR} \alpha(19,20)$ and the activation of the $\mathrm{Wnt} / \mathrm{B}$-catenin pathway promotes the development of several types of cancer, including HCC $(19,21)$. Determination of the subcellular localization of $\beta$ catenin is important since signal transduction via this protein involves its post-transcriptional stabilization and translocation into the nucleus (22). As shown in Fig. 3B, the immunohistochemical analysis demonstrated that nontumorous liver tissues showed an apparently normal Bcatenin expression pattern, namely the protein was localized predominantly on the cell membrane and occasionally in the cytoplasm, consistent with previous studies $(23,24)$. On the other hand, the strong cytoplasmic expression of the Bcatenin protein was observed uniformly throughout the HCC tissue. In some HCC cells, the protein was localized in the nucleus (Fig. 3B and D). We also found that the cyclin D1, the downstream target molecule of $\beta$-catenin (20), was strongly overexpressed in the nucleus of the HCC cells when compared to their adjacent non-tumorous regions (Fig. 3C and D). These findings suggest that $\beta$-catenin was accumulated in the cytoplasm and, in some cases, in the nucleus, thus upregulating the $\beta$-catenin/Wnt signaling pathway and subsequently increasing the expression of certain cell proliferation molecules, including cyclin D1, in the 3'-MeDABinduced HCCs in rats.

\section{Discussion}

We observed a significant decrease in the expression level of RXR $\alpha$ in 3'-MeDAB-induced liver cell neoplasms, HCCs and adenomas in rats (Figs. 1 and 2A). In particular, our findings that the expression of $\mathrm{RXR} \alpha$ was decreased in not only liver cell tumors (Fig. 1D) but also in some (25\%) of GST-P positive foci (Fig. 1L) are of interest. The findings indicate that some GST-P positive foci expressing low RXR $\alpha$ protein, but not all foci, can progress hepatocellular neoplasms, suggesting that the repression of RXR $\alpha$ occurs even in early stage of liver carcinogenesis. We have initially reported that retinol was locally deficient in the HCC but not in adjacent normal liver regions in the rodent model (25). In addition, we have found that the accumulation of non-functional $\mathrm{p}-\mathrm{RXR} \alpha$ was associated with the carcinogenesis of HCC (8). Therefore, our findings described herein, together with these studies, suggest that the loss of fundamental function of RXR $\alpha$ due to its abnormal phosphorylation or due to its substantial disappearance plays a critical role in the development of HCC, although other retinoid receptors may be involved in liver cell tumorigenesis.

In addition to $\operatorname{RXR} \alpha$, we also found in this study that the levels of RAR $\alpha$ and RAR $\beta$ proteins and their mRNAs were progressively suppressed in the HCCs and its surrounding tissue, when compared to the normal liver tissues which obtained from the control group (Fig. 2). Among the retinoid receptors, RARß appears to be relevant to epithelial carcinogenesis and chemoprevention (3). Therefore, our findings that the decrease in the expression levels of both protein and mRNA were remarkable in RARß (Fig. 2C) are of interest, since this receptor plays an important role in inhibiting the development of various types of cancer (3). Moreover, there is an impressive report on $\operatorname{RAR} \alpha$ that this receptor forms a complex with $\beta$-catenin and the reduction of the RAR $\alpha / \beta$ catenin complex caused an increase in the TCF/ß-catenin complex, thus enhancing the expression of cyclin D1 by using a transgenic mouse expressing RAR $\alpha$-dominant negative form in hepatocytes (20). B-catenin interacts directly with RAR and RAR competes with TCF for $\beta$-catenin binding (19). Additionally, $\beta$-catenin interacts with $\operatorname{RXR} \alpha$ and this interaction is also enhanced by RXR agonists (18). $\beta$-catenin is a component of the Wnt signaling pathway and the accumulation of this protein in the cytoplasm and nucleus is closely associated with development of several types of cancer, including HCCs (17-20). Therefore, these studies and our present findings that the $\beta$-catenin is immunohistochemically localized and accumulated in the cytoplasm and nucleus in the HCC cells (Fig. 3) may lead to a hypothesis that the downregulation of the retinoid receptors causes an increase in the free levels of their heterodimeric partner $\beta$-catenin, activates the $\beta$-catenin/Wnt signaling, overexpresses the cyclin D1 protein, and thus contributing to the liver carcinogenesis in the model animals used in this study. Additional studies that are ongoing in our laboratory will clarify whether loss of retinoid receptors directly enhances the $\beta$-catenin/Wnt signaling pathway or the supplementation of retinoid has effects on this signaling pathway during hepatocarcinogenesis.

In conclusion, our findings suggest that the loss of retinoid receptors, especially $\mathrm{RXR} \alpha$, plays a critical role in chemicallyinduced liver carcinogenesis in rats. We have previously reported that supplementation with an acyclic retinoid, which can inhibit the phosphorylation of $\operatorname{RXR} \alpha$ (26) and causes an increase in the levels of RAR $\alpha$ (27), significantly reduced the tumor incidence of experimental HCCs induced by a chemical carcinogen in rats as well as in the spontaneous hepatomabearing mice genetically determined $(11,25,28)$. The fact that this agent is able to inhibit the cyclin D1 promoter activity which was stimulated by $\beta$-catenin/TCF signaling pathway in HepG2 human HCC cells (29) is also important. Collectively, the restoration of the function and expression of the retinoid receptors, especially $\mathrm{RXR} \alpha$ may be a potentially effective and critical strategy for chemoprevention against HCCs development.

\section{Acknowledgements}

This study was supported in part by a Grant-in-Aid from the Ministry of Education, Science, Sports and Culture of Japan (No. 18790457 to M.S. and No. 17015016 to H.M.).

\section{References}

1. Ikeda K, Saitoh S, Koida I, et al: A multivariate analysis of risk factors for hepatocellular carcinogenesis: a prospective observation of 795 patients with viral and alcoholic cirrhosis. Hepatology 18: 47-53, 1993.

2. Shiratori Y, Yoshida H and Omata M: Different clinicopathological features of hepatocellular carcinoma in relation to causative agents. J Gastroenterol 36: 73-78, 2001.

3. Altucci L and Gronemeyer $\mathrm{H}$ : The promise of retinoids to fight against cancer. Nat Rev Cancer 1: 181-183, 2001.

4. Chambon P: A decade of molecular biology of retinoic acid receptors. FASEB J 10: 940-954, 1996.

5. Garcia AD, Ostapchuk P and Hearing P: Functional interaction of nuclear factors EF-C, HNF-4, and RXR alpha with hepatitis B virus enhancer. J Virol 67: 3940-3950, 1993. 
6. Benbrook D, Lernhardt E and Pfahl M: A new retinoic acid receptor identified from a hepatocellular carcinoma. Nature 333: 669-672, 1988.

7. de The H, Marchio A, Tiollais P and Dejean A: A novel steroid thyroid hormone receptor-related gene inappropriately expressed in human hepatocellular carcinoma. Nature 330: 667$670,1987$.

8. Matsushima-Nishiwaki R, Okuno M, Adachi S, et al: Phosphorylation of retinoid $\mathrm{X}$ receptor alpha at serine 260 impairs its metabolism and function in human hepatocellular carcinoma. Cancer Res 61: 7675-7682, 2001.

9. Matsushima-Nishiwaki R, Shidoji Y, Nishiwaki S, Yamada T, Moriwaki $\mathrm{H}$ and Muto Y: Aberrant metabolism of retinoid X receptor proteins in human hepatocellular carcinoma. Mol Cell Endocrinol 121: 179-190, 1996.

10. Adachi S, Okuno M, Matsushima-Nishiwaki R, et al: Phosphorylation of retinoid $\mathrm{X}$ receptor suppresses its ubiquitination in human hepatocellular carcinoma. Hepatology 35: 332-340, 2002.

11. Sano T, Kagawa M, Okuno M, et al: Prevention of rat hepatocarcinogenesis by acyclic retinoid is accompanied by reduction in emergence of both TGF-alpha-expressing oval-like cells and activated hepatic stellate cells. Nutr Cancer 51: 197-206, 2005.

12. Tsuda H, Park CB and Moore MA: Short- and medium-term carcinogenicity tests: simple initiation-promotion assay systems. IARC Sci Publ 146: 203-249, 1999.

13. Moriwaki H, Muto Y, Ninomiya M, Kawai K, Suzuki Y and Seto T: Inhibitory effects of synthetic acidic retinoid and polyprenoic acid on the development of hepatoma in rats induced by 3 '-methyl-N, N-dimethyl-4-aminoazobenzene. Gastroenterol Jpn 23: 546-552, 1988.

14. Fan YY, Spencer TE, Wang N, Moyer MP and Chapkin RS: Chemopreventive n-3 fatty acids activate RXRalpha in colonocytes. Carcinogenesis 24: 1541-1548, 2003.

15. Kameue C, Tsukahara T and Ushida K: Alteration of gene expression in the colon of colorectal cancer model rat by dietary sodium gluconate. Biosci Biotechnol Biochem 70: 606-614, 2006.

16. Prins GS, Chang WY, Wang Y and van Breemen RB: Retinoic acid receptors and retinoids are up-regulated in the developing and adult rat prostate by neonatal estrogen exposure. Endocrinology 143: 3628-3640, 2002.

17. Lu D, Cottam HB, Corr M and Carson DA: Repression of betacatenin function in malignant cells by nonsteroidal antiinflammatory drugs. Proc Natl Acad Sci USA 102: 18567-18571, 2005.
18. Xiao JH, Ghosn C, Hinchman C, et al: Adenomatous polyposis coli (APC)-independent regulation of beta-catenin degradation via a retinoid X receptor-mediated pathway. J Biol Chem 278: 29954-29962, 2003.

19. Easwaran V, Pishvaian M, Salimuddin and Byers S: Crossregulation of beta-catenin-LEF/TCF and retinoid signaling pathways. Curr Biol 9: 1415-1418, 1999.

20. Yanagitani A, Yamada S, Yasui S, et al: Retinoic acid receptor alpha dominant negative form causes steatohepatitis and liver tumors in transgenic mice. Hepatology 40: 366-375, 2004.

21. Lustig B and Behrens J: The Wnt signaling pathway and its role in tumor development. J Cancer Res Clin Oncol 129: 199-221, 2003.

22. Rubinfeld B, Albert I, Porfiri E, Fiol C, Munemitsu S and Polakis P: Binding of GSK3beta to the APC-beta-catenin complex and regulation of complex assembly. Science 272: 1023-1026, 1996

23. de La Coste A, Romagnolo B, Billuart P, et al: Somatic mutations of the beta-catenin gene are frequent in mouse and human hepatocellular carcinomas. Proc Natl Acad Sci USA 95: 8847-8851, 1998.

24. Nhieu JT, Renard CA, Wei Y, Cherqui D, Zafrani ES and Buendia MA: Nuclear accumulation of mutated beta-catenin in hepatocellular carcinoma is associated with increased cell proliferation. Am J Pathol 155: 703-710, 1999.

25. Muto Y and Moriwaki H: Antitumor activity of vitamin A and its derivatives. J Natl Cancer Inst 73: 1389-1393, 1984

26. Matsushima-Nishiwaki R, Okuno M, Takano Y, Kojima S, Friedman SL and Moriwaki H: Molecular mechanism for growth suppression of human hepatocellular carcinoma cells by acyclic retinoid. Carcinogenesis 24: 1353-1359, 2003.

27. Shimizu M, Suzui M, Deguchi A, Lim JT and Weinstein IB: Effects of acyclic retinoid on growth, cell cycle control, epidermal growth factor receptor signaling, and gene expression in human squamous cell carcinoma cells. Clin Cancer Res 10: 1130-1140, 2004.

28. Kagawa M, Sano T, Ishibashi N, et al: An acyclic retinoid, NIK-333, inhibits N-diethylnitrosamine-induced rat hepatocarcinogenesis through suppression of TGF-alpha expression and cell proliferation. Carcinogenesis 25: 979-985, 2004.

29. Suzui M, Masuda M, Lim JT, Albanese C, Pestell RG and Weinstein IB: Growth inhibition of human hepatoma cells by acyclic retinoid is associated with induction of p21(CIP1) and inhibition of expression of cyclin D1. Cancer Res 62: 3997-4006, 2002. 